\title{
Imparting Barely Visible Impact Damage to a Stitched Composite Large-Scale Pressure Box
}

\author{
Andrew E. Lovejoy ${ }^{1}$ and Adam Przekop ${ }^{1}$ \\ NASA Langley Research Center, Hampton, Virginia, 23681
}

\begin{abstract}
The Pultruded Rod Stitched Efficient Unitized Structure (PRSEUS) is a concept that was developed by The Boeing Company to address the complex structural design aspects associated with a pressurized hybrid wing body (HWB) aircraft configuration, which has been a focus of the NASA Environmentally Responsible Aviation Project. The NASA-Boeing structural development for the HWB aircraft culminated in testing of the multi-bay box, which is an $80 \%$-scale representation of the pressurized center-body section. This structure was tested in the NASA Langley Research Center Combined Loads Test System facility. As part of this testing, barely visible impact damage was imparted to the interior and exterior of the test article to demonstrate compliance with a condition representative of the requirements for Category 1 damaged composite structure as defined by the Federal Aviation Regulations. Interior impacts were imparted using an existing spring-loaded impactor, while the exterior impacts were imparted using a newly designed, gravity-driven impactor. This paper describes the impacts to the test article, and the design of the gravitydriven guided-weight impactor. The guided-weight impactor proved to be a very reliable method to impart barely visible impact damage in locations which are not easily accessible for a traditional drop-weight impactor, while at the same time having the capability to be highly configurable for use on other aircraft structures.
\end{abstract}

\section{Introduction}

The Pultruded Rod Stitched Efficient Unitized Structure (PRSEUS) ${ }^{1}$ is a concept that has been developed by The Boeing Company (Boeing) to address the complex structural design aspects associated with a pressurized hybrid wing body (HWB) aircraft configuration as shown in Fig. 1. The HWB has been a focus of the NASA Environmentally Responsible Aviation (ERA) Project, with structural development primarily addressing the pressurized, non-circular fuselage portion of the HWB. PRSEUS is an integral structural concept whereby skins, frames, stringers, and tear straps are all stitched together, then infused and cured in an out-of-autoclave process. The PRSEUS concept, as it has been applied to pressurized HWB fuselage structure, is shown in Fig. 2. The concept has evolved from stitching technology development activities in several NASA-Boeing and Air Force Research Lab (AFRL)-Boeing programs beginning in the 1990's. ${ }^{2-5}$ The key to the PRSEUS concept is the pre-cured, pultruded rod that is contained within the stringer wrap plies and which passes through the frames, providing an uninterrupted load path in the stringer direction. At the same time, the full height frame stiffener is also continuous, except for the keyhole through which the stringer passes, providing an uninterrupted load path in the direction perpendicular to the stringer. These efficient structural stiffening members provide the majority of the panel stiffness, permitting the use of minimum skin thickness for many applications. For example, typical PRSEUS stringer and frame cross-sections examined for HWB fuselage-type structure are shown in Fig. 3, where the skin is minimum gage and the stringer and frame are the main load carrying components. ${ }^{6,7}$ Minimum gage is a stack of 9 layers of carbon/epoxy material that is 0.052 inches thick. Typical stringers in the HWB design use only a single stack for the stringer, which creates a two-stack web and single-stack wrap around the rod at the top of the stiffener.

Throughout ERA, the building block approach has been used to design, analyze, build, and test HWB PRSEUS structural components leading to an $80 \%$-scale center portion of the HWB as shown in Fig. 4 and identified in the lower right portion of the figure. Testing of the $80 \%$-scale Multi-bay Box (MBB) in the Combined Loads Test System (COLTS) Facility at NASA Langley Research Center (LaRC) ${ }^{8,9}$ began in April 2015. The MBB was subjected to a series of load cases with testing being concluded in May after the infliction of discrete source damage

\footnotetext{
${ }^{1}$ Research Aerospace Engineer, Structural Mechanics and Concepts Branch, 8 West Taylor Street, Mail Stop 190,
} Associate Fellow AIAA. 
to the top of the test article. A photograph of the test article between the platens in the COLTS Facility and a graphical representation of the COLTS arrangement are shown in Fig. 5. Actuators connected to the platens are used to apply mechanical loads to the test article. Pressure loading was applied using a highpressure feed line that was connected to the MBB. Five loading conditions were applied to the pristine MBB in a series of experiments under design limit load (DLL) and then design ultimate load (DUL) levels. These loading conditions were 1) an internal pressure load alone where DUL is $18.4 \mathrm{psi}$; 2) a load simulating a 2.5 -g wing up-bending condition which subjects the crown panel to compressive loads; 3 ) a -1-g wing down-bending condition which subjects the crown panel to tensile loads; 4) a combination of pressure and -1-g wing down-bending; and 5) a

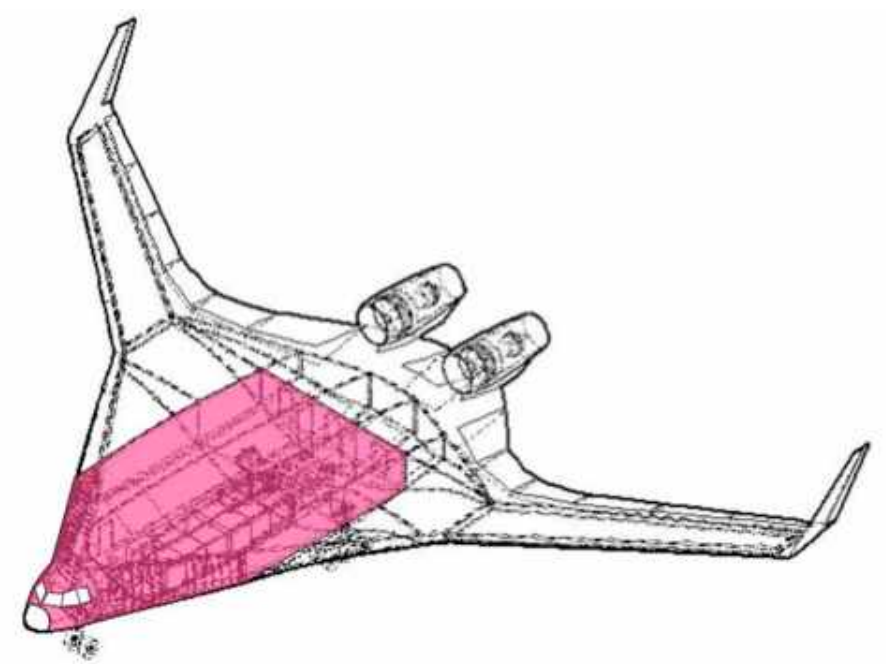

Figure 1. Typical pressurized portion of a HWB aircraft concept, indicated by red shaded area.

combination of pressure and 2.5-g wing up-bending. Details of the testing and results are presented in Refs. 10-12. Included within the testing was a repeated set of the five load conditions after barely visible impact damage (BVID) was introduced. BVID was introduced to satisfy conditions representative of the requirements in the Federal Aviation Regulations (FAR) requirements, PART 25-Airworthinesss Standards: Transport Category Airplanes), ${ }^{13}$ which is summarized in Ref. 14. The requirement is that composite structures with Category 1 damage, including BVID, shall demonstrate a reliable service life while retaining ultimate load capability. How BVID was imparted to the MBB and the development of a guided drop weight impactor that was used to impart BVID to the exterior of the MBB is described in the current paper.

\section{Impact Requirements}

To satisfy conditions representative of the BVID requirements, ${ }^{13,14}$ the MBB had to be impacted with energy levels sufficient to impart BVID, but with an energy level not to exceed maximum values for interior and exterior impacts of $20 \mathrm{ft}-1 \mathrm{~b}$ and $100 \mathrm{ft}-\mathrm{lb}$, respectively. In order to determine energy levels that were below the maximum values, which would result in BVID to various locations within the MBB PRSEUS structure, a series of tests were carried out at Boeing and LaRC. For interior impacts, it was determined that a $15 \mathrm{ft}-\mathrm{lb}$ energy level would result in BVID on the skin, and that the top of the stringer and frame could withstand the maximum $20 \mathrm{ft}-\mathrm{lb}$ level. For exterior impacts, it was determined that the skin would show BVID with the $15 \mathrm{ft}-1 \mathrm{~b}$ level, while the stringer and frame flanges would exhibit BVID at $50 \mathrm{ft}-1 \mathrm{~b}$ and $60 \mathrm{ft}-\mathrm{lb}$ levels, respectively. A summary of the required impacts for the MBB is provided in Table 1, and the corresponding impact locations are identified and their locations on the MBB are shown in Fig. 6. Exterior impacts at the stringer and frame flanges means impact of the skin that is backed

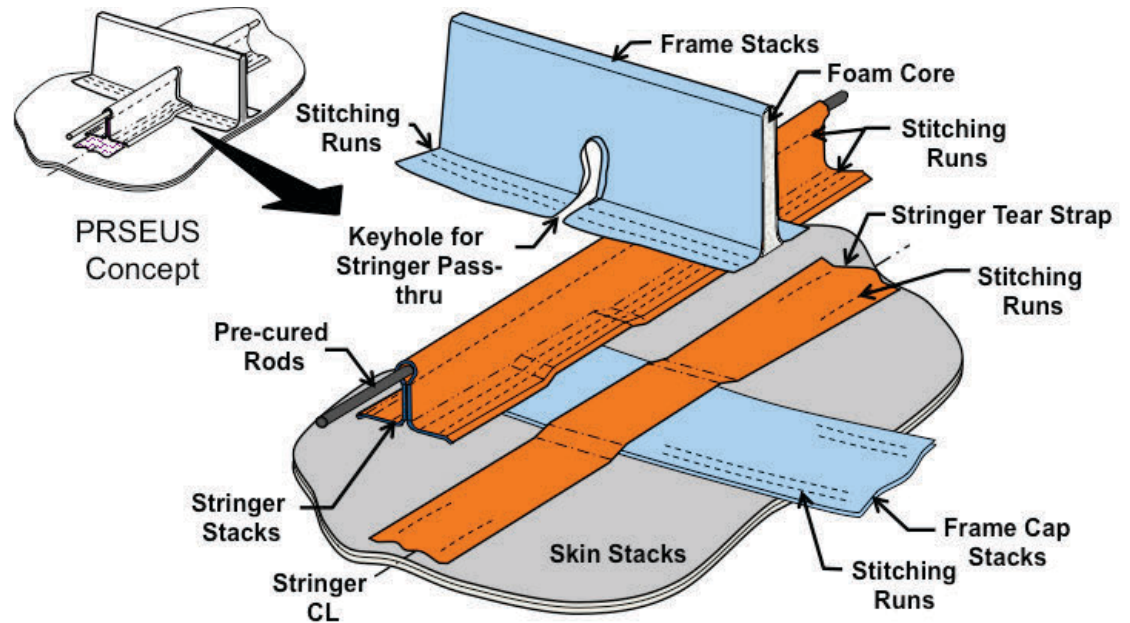

by the flanges, giving the thicker skin/flange region as seen in the figure. The interior impacts would be conducted using an existing $3.708 \mathrm{lb}$ weight, while the exterior impacts would use a $5-\mathrm{lb}$ weight for the $15 \mathrm{ft}-\mathrm{lb}$ energy and a $15-1 b$ weight for the $50 \mathrm{ft}-\mathrm{lb}$ and $60 \mathrm{ft}-\mathrm{lb}$ energies. Lastly, the impact weight indentor, or tup, was required to follow standard practice and have a 1-inch hemi-spherical shape.

Figure 2. Typical PRSEUS concept. 


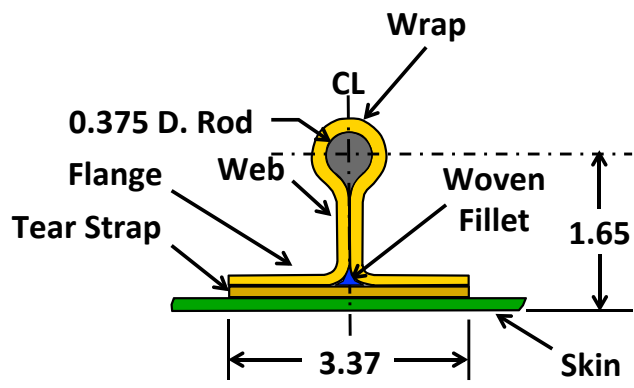

a) Stringer

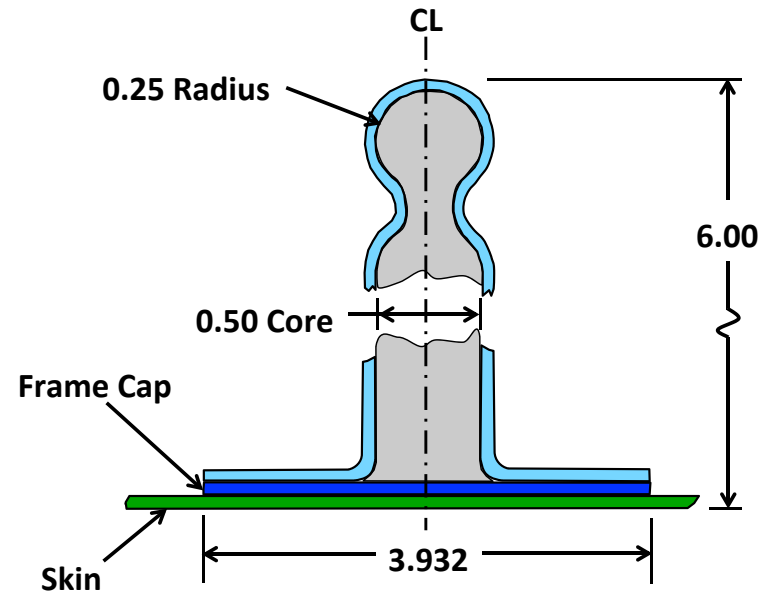

b) Frame

Figure 3. Typical pressurized HWB fuselage frame and stringer cross-sections. Dimensions are in inches, and typical stack values are shown for stringer.

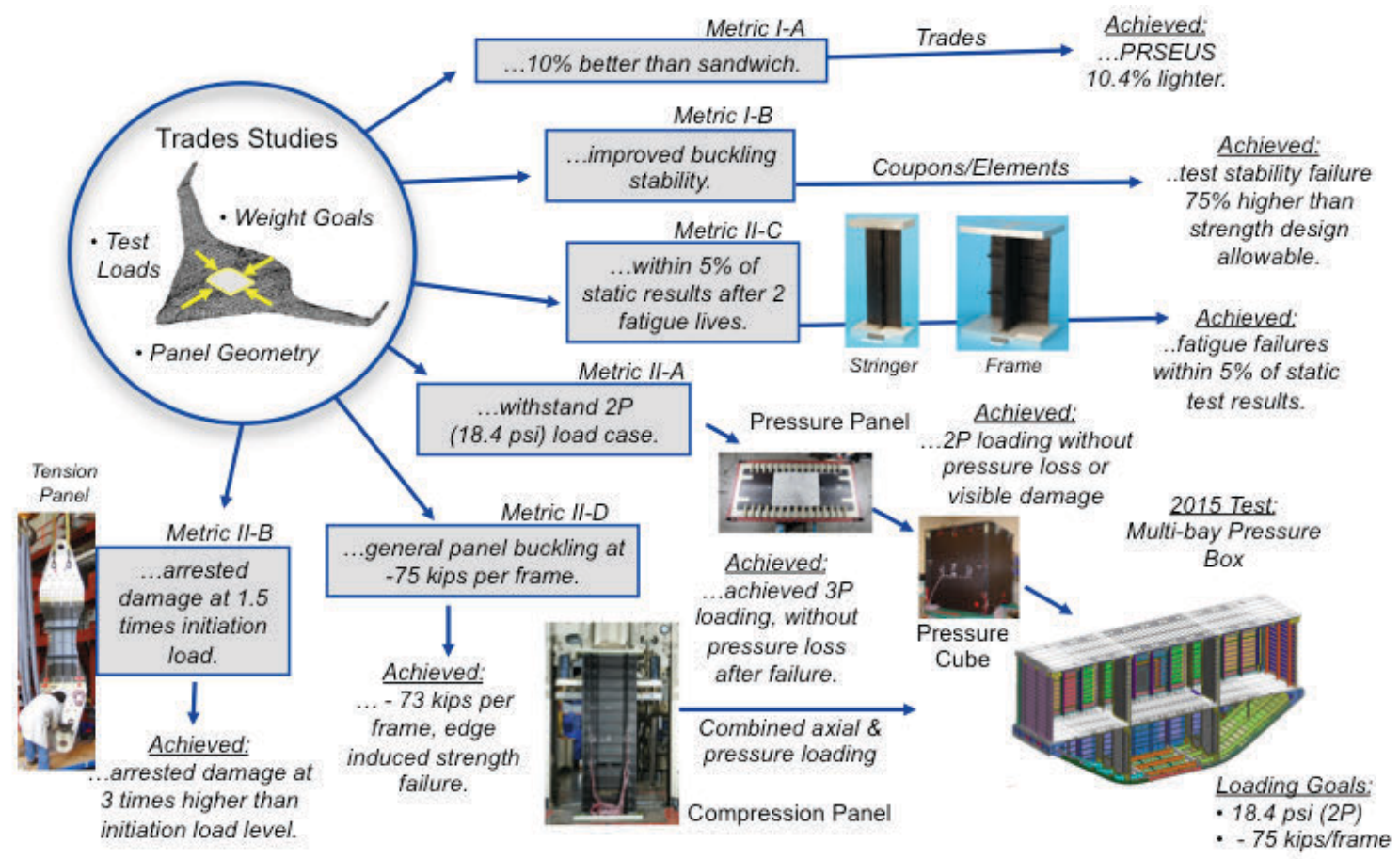

Figure 4. HWB structural development building-block approach.

\section{Interior Impacts}

Interior impacts were performed using the portable spring-loaded impactor that was used for impacts on the composite crew module. ${ }^{15}$ This impactor was chosen as it has been demonstrated as suitable for the appropriate impact levels on numerous composite structures, including a PRSEUS pressure panel. ${ }^{16}$ The impactor is shown in Fig. 7, with components labeled. A force-time history is measured using an integral load cell, and the velocity at impact is measured using a flag and optical gate. Calibration of the impactor was performed by adjusting the threaded actuator rod throughout various trial runs. The initial compression value was set by determining the required spring compression based on the target velocity, the spring constant, the impact weight, and the angle of attack of the impactor under the assumption of frictionless operation as defined in Ref. 15. The impactor was held in position during the impacts by means of support structure that was clamped to the MBB structure, as shown in Fig. 8 


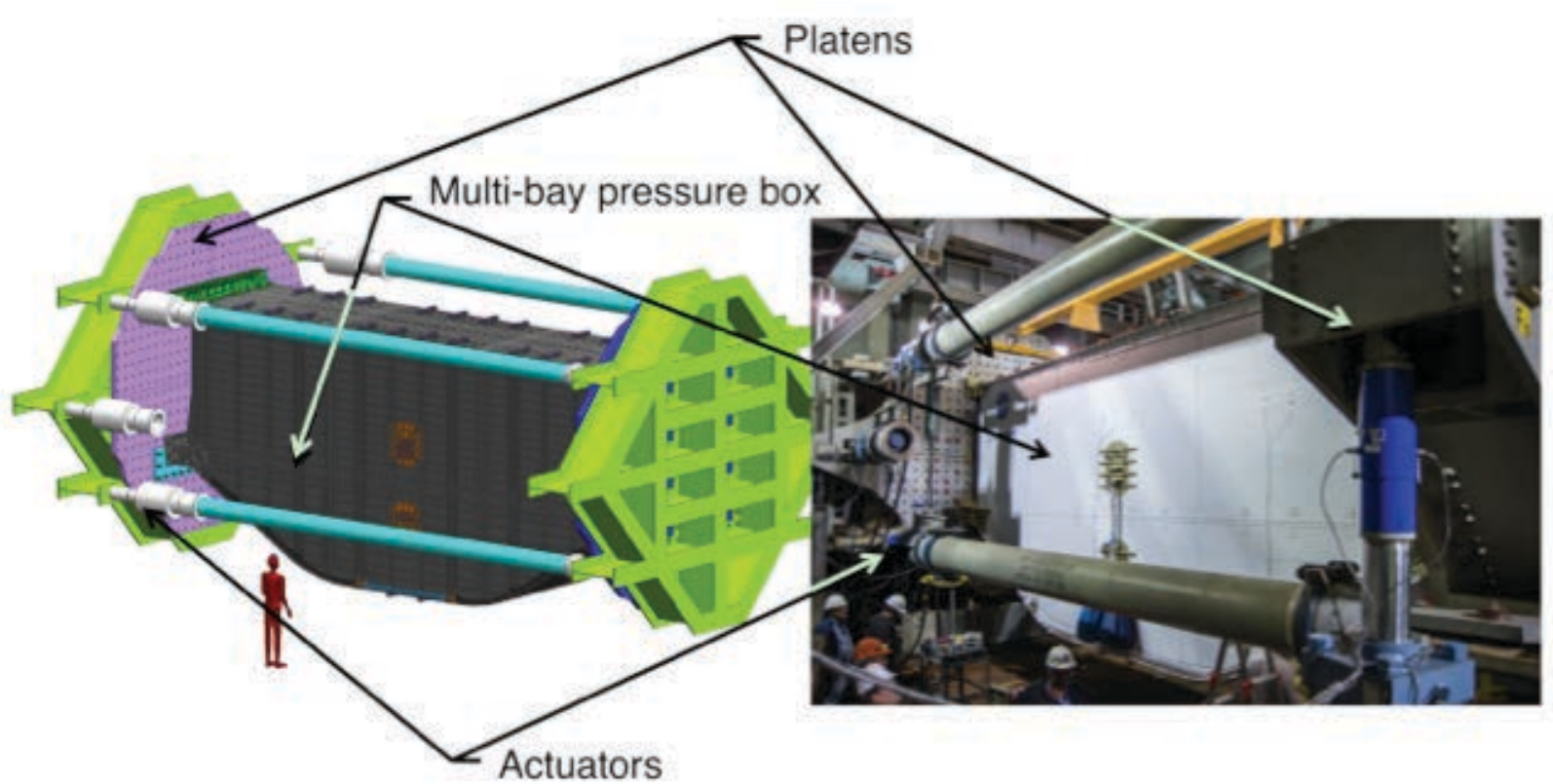

a) Graphical representation

b) Photo in COLTS test chamber

Figure 5. Multi-bay pressure box graphical representation and photograph of MBB in COLTS test chamber.

for the interior skin impact. A bubble level was affixed to the top of the aluminum tube to ensure that the impactor was horizontal at the time of operation. Operation of the impactor required two operators, one to stabilize the impactor and one to pull the pin to release the spring-loaded weight, as shown in Figure 9. The interior skin impact (I3) is shown in Fig. 10. The dent depth of the impact, as measured on the inner skin surface, was 0.097 inches and the indentation was approximately 0.62 inches in diameter. For this impact, the target velocity was $16.14 \mathrm{ft} / \mathrm{s}$, while the actual velocity at impact was $17.50 \mathrm{ft} / \mathrm{s}$, resulting in an impact energy of $17.65 \mathrm{ft}-\mathrm{lb}$ and an error of about $8.43 \%$ when compared to the $15 \mathrm{ft}-\mathrm{lb}$ requirement. Variability of the velocity for the two $20 \mathrm{ft}-1 \mathrm{~b}$ impacts was also observed, with the frame (I1) and stringer (I2) impact velocities of $18.85 \mathrm{ft} / \mathrm{s}$ and $19.58 \mathrm{ft} / \mathrm{s}$, respectively, when compared to the target velocity of $18.63 \mathrm{ft} / \mathrm{s}$. Frame and stringer impact velocities exceeded the target velocity with errors of $1.18 \%$ and $5.10 \%$, respectively. No discernable visible damage was observed on the frame and stringer after the impacts at the maximum required interior impact energy level. Table 2 summarizes the target velocities, actual velocities, and errors for the three interior impacts.

\section{Exterior Impacts}

The exterior impacts required a greater impact energy and heavier impact weights than the interior impacts. Specifically, recall the requirement was that the skin impact use a 5-lb weight and the frame and stringer flange impacts use a 15-lb weight. Traditionally, large weights are used in a drop-weight impactor, whereby gravity accelerates the weight to obtain the correct impact energy, and the impact damage is imparted to the top surface of the test article. Such a method has been used on numerous structures including the curved PRSEUS panel tested at the Federal Aviation Administration (FAA) ${ }^{17}$ testing facility and the PRSEUS cube tested at NASA LaRC. ${ }^{6,7}$ In the case of the cube, the test article was rotated on its side, so that the impact site was oriented upward to facilitate the use of the drop-weight impactor. However, the exterior impacts on the MBB were imparted to the center keel, or the underside of the MBB. Unfortunately, the MBB could not be rotated to orient the impact sites upward as was done with the cube. Therefore, a device was needed that could be used to impact the center keel with the impact weight moving upwards at impact, while at the same time restraining the motion of the impact weight to ensure impact occurred at the desired location. In order to impact in this manner, a design study was undertaken to develop a means of easily and reliably imparting BVID to the center keel. 
Table 1. Summary of MBB impact locations and energy.

\begin{tabular}{|c|c|c|c|c|}
\hline \multicolumn{5}{|c|}{ Interior } \\
\hline ID & Description & Energy (ft-lb) & Weight (lb) & Velocity (ft/s) \\
\hline I1 & $\begin{array}{c}\text { Upper Forward Bulkhead, } \\
\text { Frame Top }\end{array}$ & 20 & 3.708 & 18.63 \\
\hline I2 & $\begin{array}{c}\text { Upper Forward Bulkhead, } \\
\text { Stringer Top }\end{array}$ & 20 & 3.708 & 18.63 \\
\hline I3 & $\begin{array}{c}\text { Upper Forward Bulkhead, } \\
\text { Center Skin Bay }\end{array}$ & 15 & 3.708 & 16.14 \\
\hline
\end{tabular}

\begin{tabular}{|c|c|c|c|c|}
\hline \multicolumn{5}{|c|}{ Exterior } \\
\hline ID & Description & Energy (ft-lb) & Weight (lb) & Velocity (ft/s) \\
\hline E1 & Keel, Frame Flange & 60 & 15 & 16.04 \\
\hline E2 & Keel, Stringer Flange & 50 & 15 & 14.65 \\
\hline E3 & Keel, Center Skin Bay & 15 & 5 & 13.89 \\
\hline
\end{tabular}

Numerous methods were available to propel the impact weight upwards at impact. Methods considered included gas-propelled weight, spring-propelled weight, gravity-driven pendulum, gravity-driven pulley/weight system, and a gravity-driven guided drop weight. A primary driving factor in the design of the impactor was the constrained distance between the center keel and the floor of COLTS, which was only about 38 inches. This short distance would require any gas or spring propelled weight, which for this type of impactor is usually constrained to straight

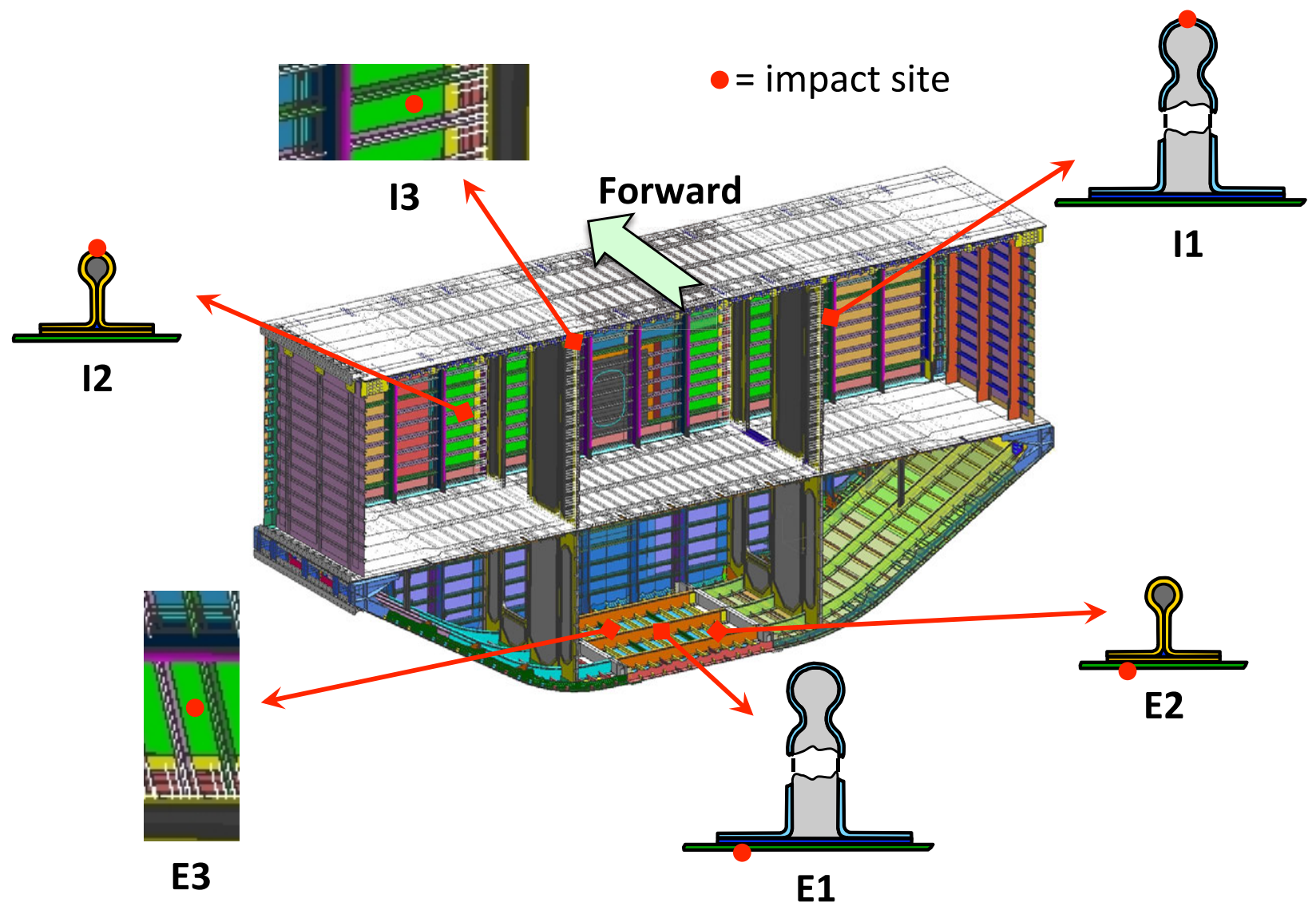

Figure 6. MBB impact locations.

5

American Institute of Aeronautics and Astronautics 
line motion, to accelerate very rapidly over an extremely short distance. Consider that the weight would have some reasonable length, say 6 inches, and the spring would be an additional distance of 6-12 inches. The weight acceleration length would be no greater than 24 inches since there should be some travel distance without force being applied by the spring. During this unforced distance, gravity would be acting against the weight, meaning that the velocity at the point of loss of contact with the spring would have to be even higher than the velocity required at impact. A similar problem exists with a gas propelled weight as there is still the need for travel without pressure driving the weight, but since it may be possible to use a shorter distance to form the initial pressure volume, the distance available for accelerating the weight might be slightly higher, a maximum of approximately 29 inches. Additionally, with the limited prelaunch volume available for the spring and gas, the spring constant and the pressure level would be large, and slight changes in weight position could lead to too significant variation in the final velocity at impact. The limited acceleration distance, combined with the variability in velocity expected to be seen with spring and gas propelled weights, eliminated these methods as an option. Therefore, a gravity-driven design was chosen to be the most repeatable and reliable method of imparting energy to the weight for the impacts. ${ }^{18}$

A pendulum device was considered, but was also eliminated due to the short height between the keel and the floor. Since an impact was required near the center of the center keel, the impactor had to be able to reach that location on the MBB, which was a similar distance as the distance between the keel and the COLTS floor. This dimensional constraint made a pendulum device incapable of providing the required motion for impact. Another gravity-driven impactor that was considered and eliminated was a pulley system design that used a dropped weight to impart motion to the impact weight. The pulley design system was also constrained by the need to rapidly accelerate the impact weight in the very limited height. This option was deemed to be too complex, both in terms of the pulley system required to convert the downward motion of the dropped weight into the appropriate upward motion of the impact weight and in constraining the path of the impact weight for accurately impacting the correct location. Therefore, the guided drop-weight impactor was selected, designed, built, and used to impart BVID to the MBB exterior. ${ }^{18}$

The guided drop weight impactor is a gravity-driven system that was designed using the following set of requirements: 


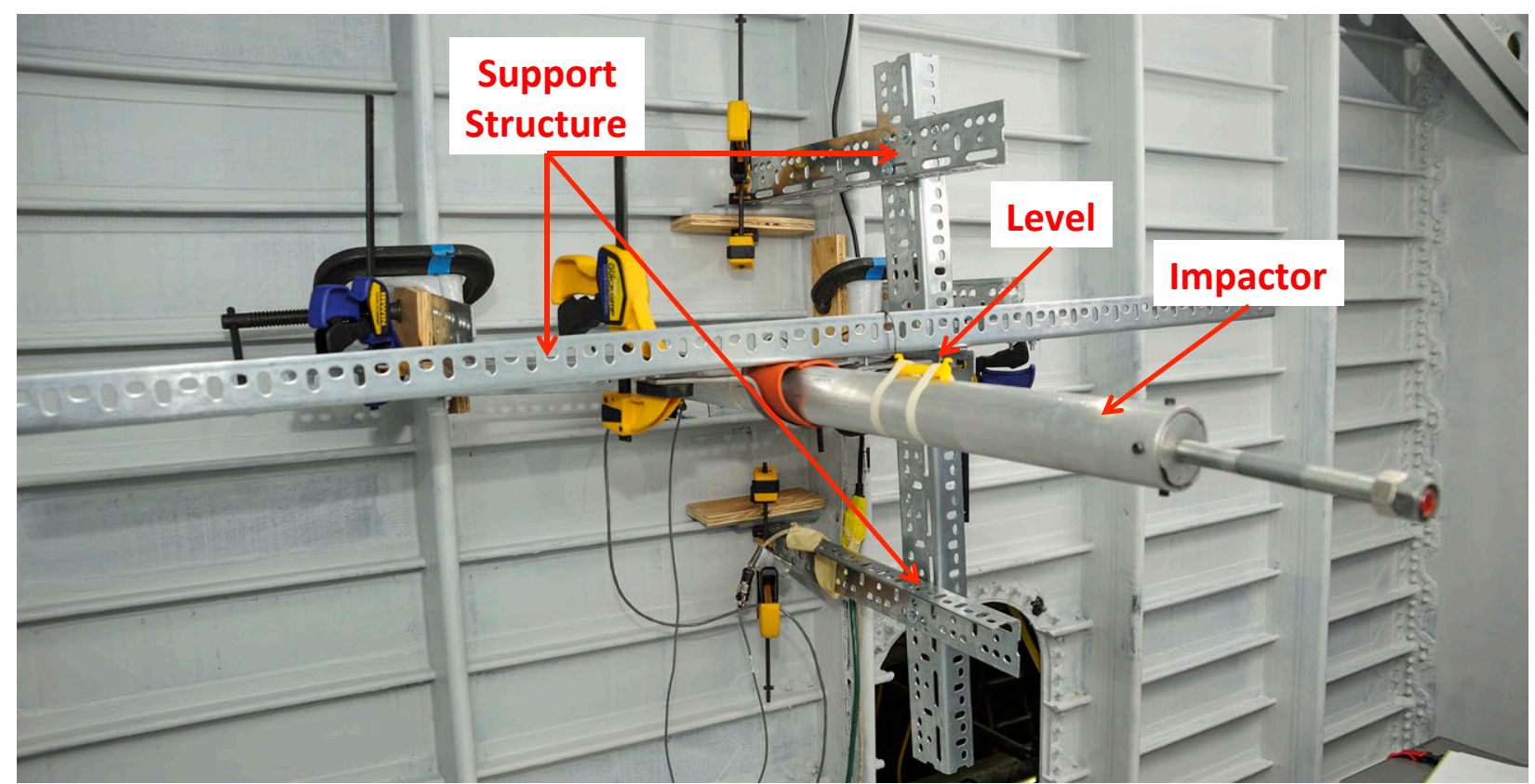

Figure 8. Set-up in the COLTS Facility for interior impact on the MBB skin.

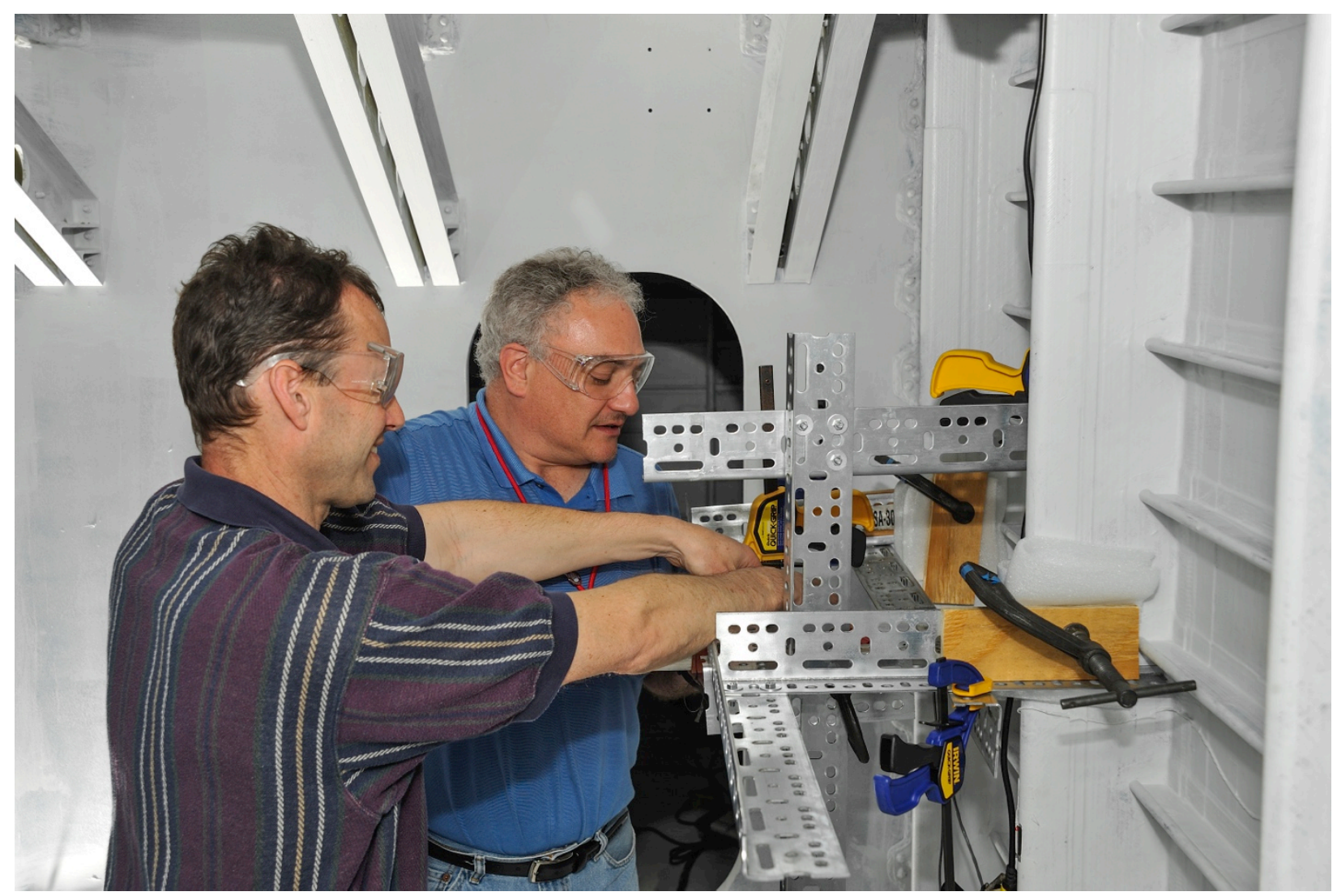

Figure 9. Imparting an interior impact to the MBB skin. 


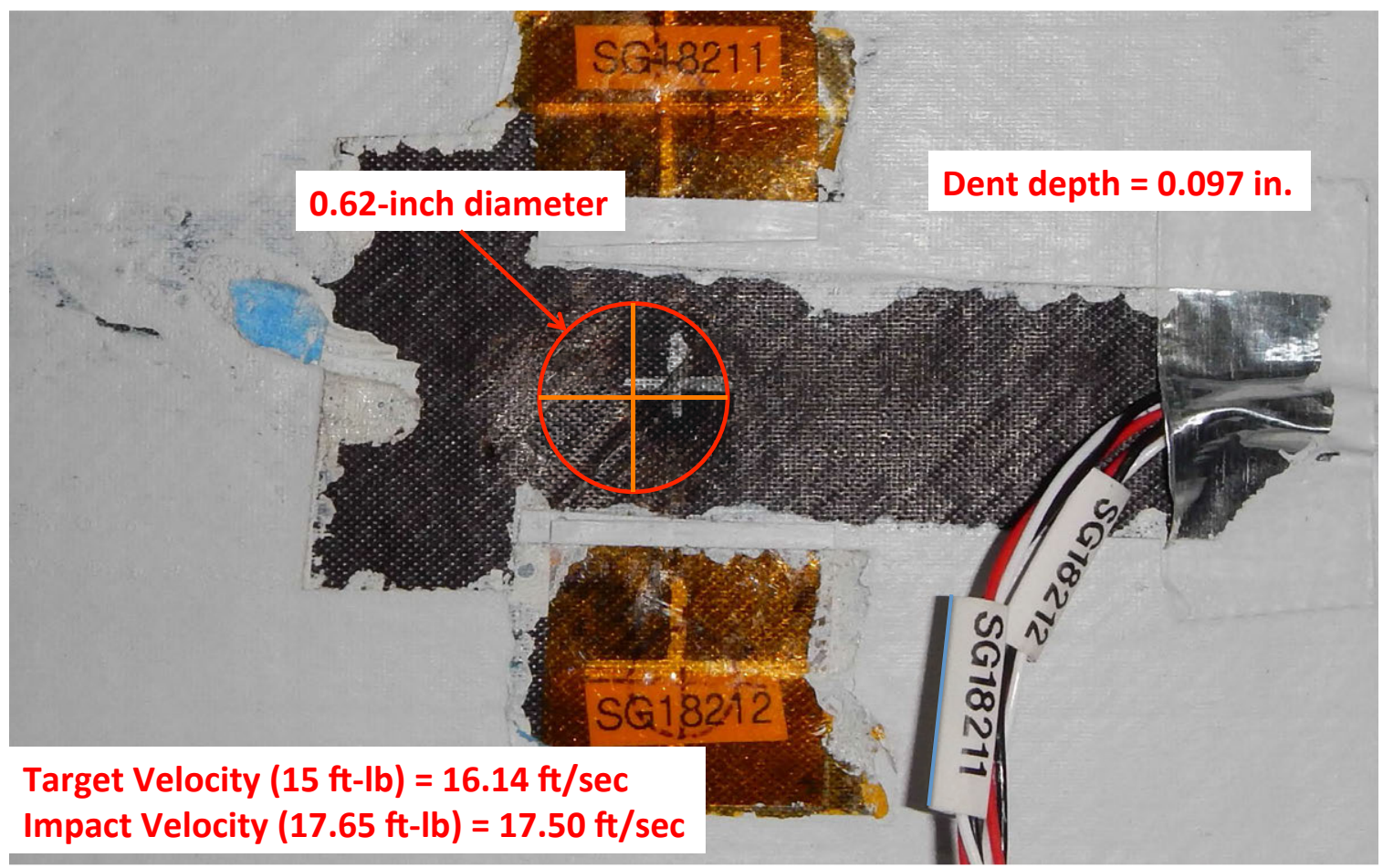

a) Interior surface, where the orange cross indicates impact location.

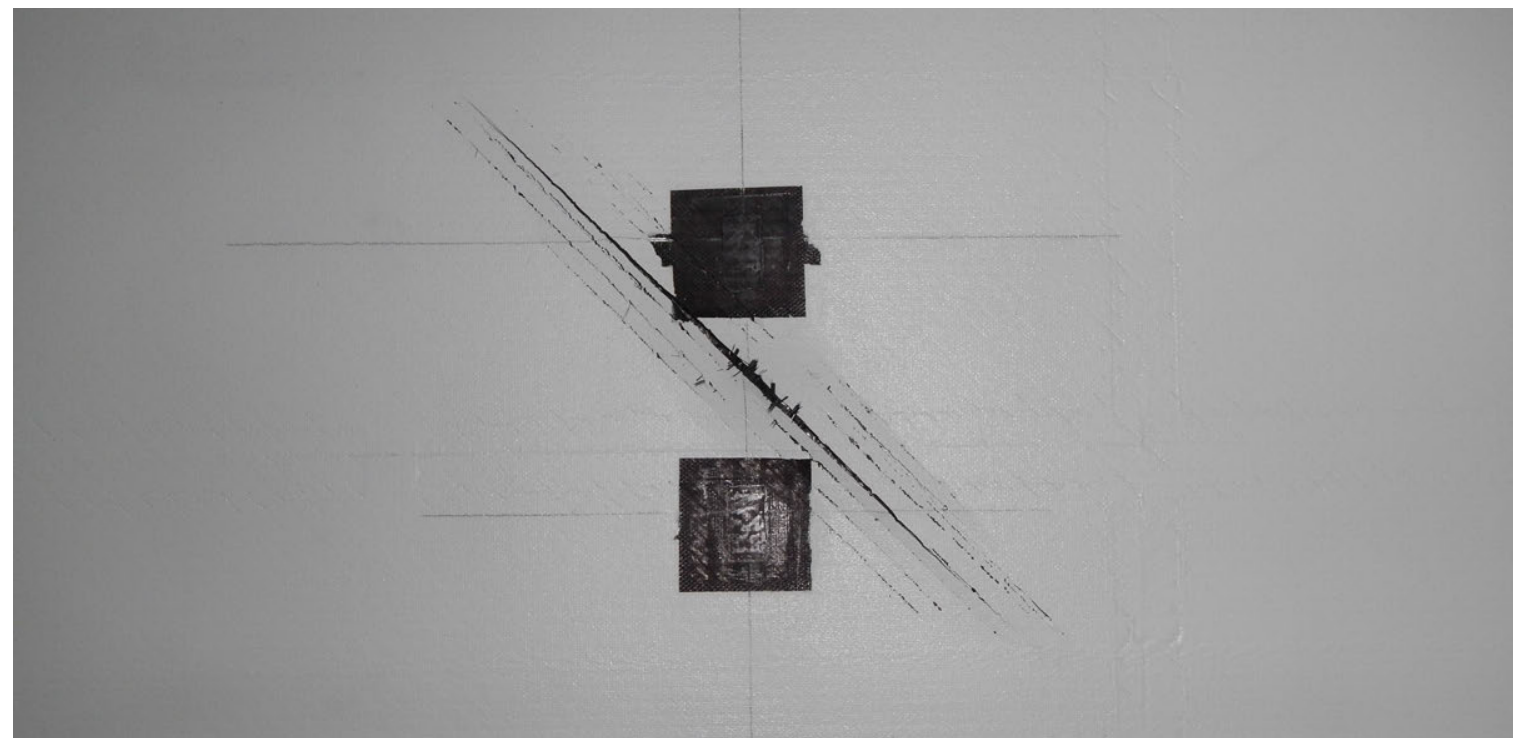

b) Exterior surface

Figure 10. Upper forward bulkhead after interior skin impact.

1. Impact weights of 5-lb and $15-1 \mathrm{~b}$ must be accommodated.

2. The impact weight must have a 1-inch hemi-spherical tup.

3. The weight must be constrained at impact to ensure desired orientation and location at the time of impact.

4. The maximum required exterior impact velocity shown in Table 1 must be achievable, while accounting for potential energy loss due to friction or other sources.

5. The impactor must be able to be positioned in COLTS to produce BVID at the required locations.

8

American Institute of Aeronautics and Astronautics 
Table 2. Summary of MBB interior impact velocities, $\mathrm{ft} / \mathrm{s}$, and errors.

\begin{tabular}{|c|c|c|c|c|}
\hline ID & Description & Target Velocity & Actual Velocity & Error (\%) \\
\hline I1 & $\begin{array}{c}\text { Upper Forward Bulkhead, } \\
\text { Frame Top }\end{array}$ & 18.63 & 18.85 & 1.18 \\
\hline I2 & $\begin{array}{c}\text { Upper Forward Bulkhead, } \\
\text { Stringer Top }\end{array}$ & 18.63 & 19.58 & 5.1 \\
\hline I3 & $\begin{array}{c}\text { Upper Forward Bulkhead, } \\
\text { Center Skin Bay }\end{array}$ & 16.14 & 17.5 & 8.43 \\
\hline
\end{tabular}

As designed, the guided drop weight impactor consists of two main components, namely the guided impact weight and the guide track. The impact weight runs along the track and is constrained at impact to be moving in the specified direction, which for the MBB was vertically. To satisfy the two required impact weight values, design of the impact weight resulted in a baseline 5-1b weight that is configurable to $15-1 \mathrm{~b}$ by adding weight blocks. The basic components of the impact weight are defined in Fig. 11, with the two configurations used to impact the MBB shown in Fig. 12. In fact, the configurable design actually enables the impact weight to be configured to any value of $5 \mathrm{lbs}$ or greater, provided that the added weights don't interfere with the track or other obstacles. The impact tup is attached to the base weight using a threaded stud, so that if desired, the shape of the impact tup can be changed to a different geometry. Two sets of 4 wheels each are attached to wheel brackets to guide the weight on the track. The wheel brackets are attached to the base weight using four bolts and spacers (which in the 15-lb configuration are replaced by two of the added weights) that position the wheels at the proper width for the track. Tabs on the wheel brackets, adjacent to each of the wheels, ensure that at no time can the weight be ejected off the track, enabling the weight to only be able to exit the track at the ends. In order to ensure that the baseline impact weight is $5 \mathrm{lbs}$, the remainder of the components were designed and chosen such that their total weight was just under $5 \mathrm{lbs}$. A weight adjustment screw was added on the end of the base weight, opposite the impact tup, by which washers or other small weights could be added to tune the total weight to the required $5 \mathrm{lbs}$. The 15-lb version of the impact weight was similarly tuned to the required weight.

The track, shown in Fig. 13, consists of two portions, namely the main track and the capture track, and is approximately $12-\mathrm{ft}$ long, $3-\mathrm{ft}$ wide, and $10-\mathrm{ft}$ tall. The main track provides the height required to impart the necessary energy level. However, a portion of the main track works with the capture track to constrain the motion of the weight at the end of the track during impact. The capture track restrains the weight at impact by holding the weight against the main track, to guide the weight to the correct location at impact. As utilized on the MBB, the track was configured to have the impact weight traveling vertically upward at impact, however, the track could be configured to have impact imparted at nearly any angle away from vertically downward. For example, the track could be configured to impact normal to a circular fuselage at the 45-degree location, as measured from the keel of the fuselage towards the side. Depending on the impact energy and the structural response to the impact, it may be necessary to capture the weight (or insert a protective element such as a paddle) after initial impact to avoid a secondary impact event. As the angle moves away from vertically upward, the need to capture the weight after

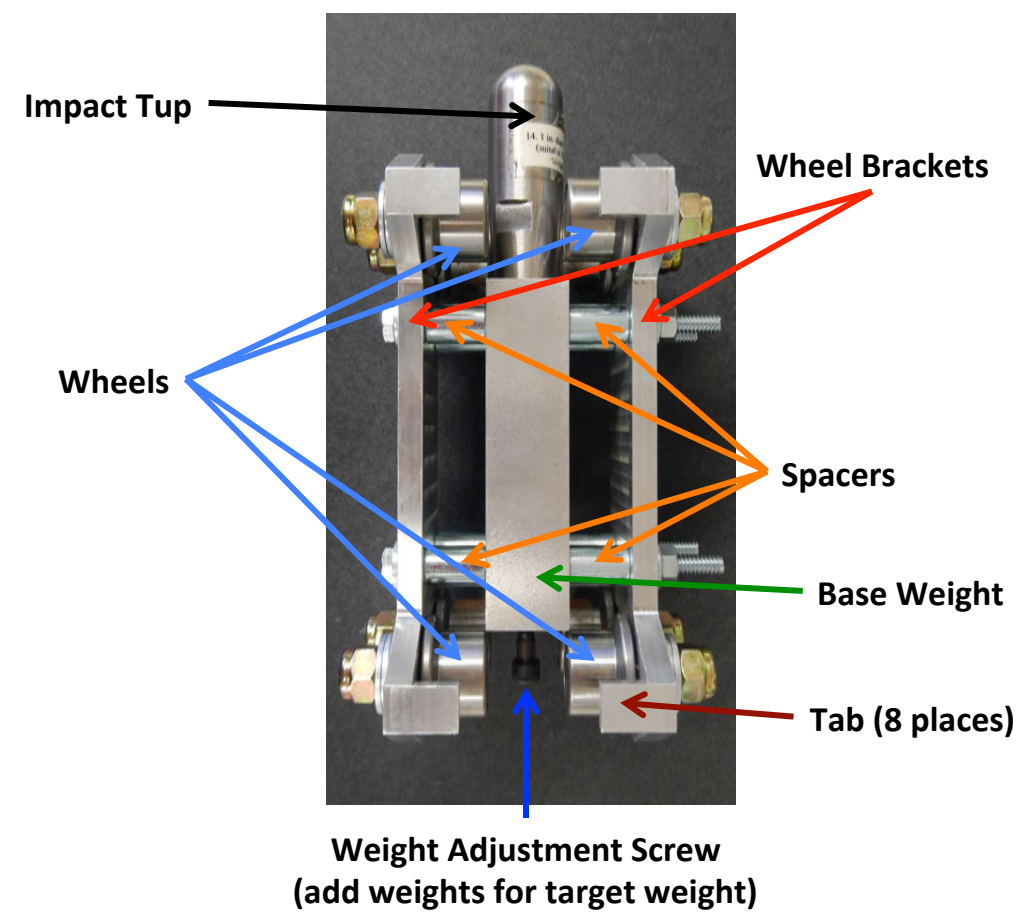

Figure 11. Baseline guided impact weight components.

9

American Institute of Aeronautics and Astronautics 


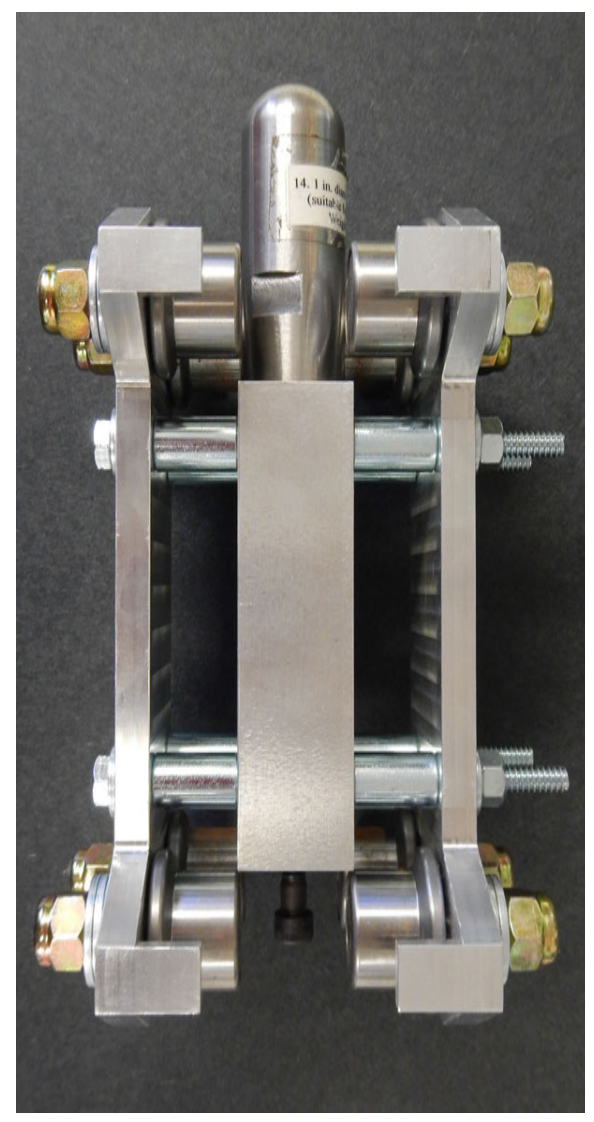

a) 5 -lb

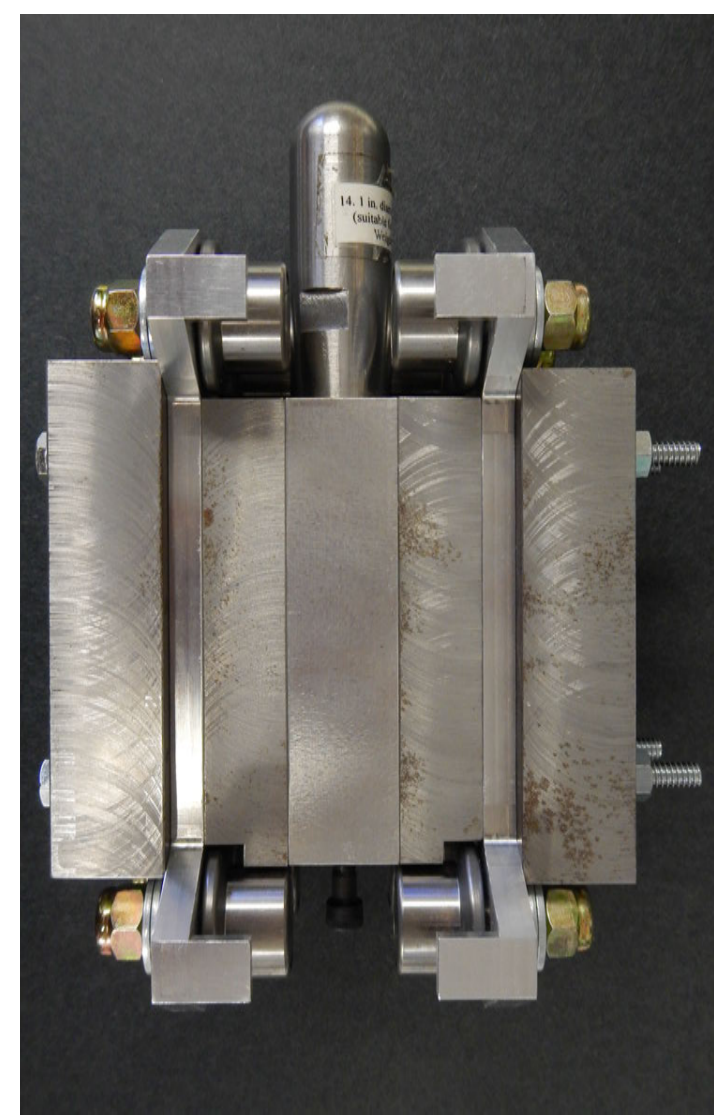

b) 15-lb

Figure 12. Pictures of the two configurations of the impact weight used to impact the MBB.

applying the required impact increases in order to eliminate the chance for double impact. The track is mounted to a base, and is supported in the area of the capture track and the areas of high force, such as where the weight is changing direction along the curved portion of the track adjacent to the base, by a plate to provide a more rigid track. Six wheels are mounted on the base to allow for ease of movement of the track. The wheels have rubber supports that can be lowered in order to raise the wheels off the ground, which are used to level the track base, and to help prevent movement of the track assembly while the impacts are being applied.

Calibration of the guided drop weight impactor was performed by impacting a wooden representation of the keel from various heights for each of the two weight configurations, and by measuring the velocity at impact using highspeed cameras. Phantom high speed cameras from Vision Research, and the associated software provided with the cameras, were used to make the velocity measurements. ${ }^{19}$ An example screen capture from one of the calibration trials for the 5-1b weight is shown in Fig. 14. To ensure consistency in the velocity measurement process, a bowtie marker and a scale were added to the impact tup and capture track support, respectively, as identified in the figure. The bowtie marker was used to provide a consistent point to measure, and the scale was attached to the capture track support in a plane that was perpendicular to the camera axis, and which contained both the scale and the bowtie marker. The removable wood impact sample was used to provide a fresh surface for the impacts, which also enabled development of the alignment process by examining the location of each impact compared to the target location that had been drawn onto the wood. An example of the wood after an impact is shown in Fig. 15, where it can be seen that the impactor could be aligned to impact the proper location with very good accuracy. After calibration for each impact energy, the track was marked to indicate the weight release location for performing the impacts to the MBB.

The impactor was used to impact the MBB while it was installed in the COLTS facility. The track in position to impart the skin BVID is shown in Fig. 16. Alignment of the impactor for applying the exterior skin impact is shown in Fig. 17. The impactor was leveled using a level on the track base, and the impact weight was held in place while the tup was aligned with the impact location mark on the MBB. In the figure, weights on the floor at the capture end of the impactor are identified. These weights were placed tight against the end of the impactor while the impact was being imparted to provide reactive support in order to prevent the impactor from moving when the weight was 


\section{Impact Capture Area}
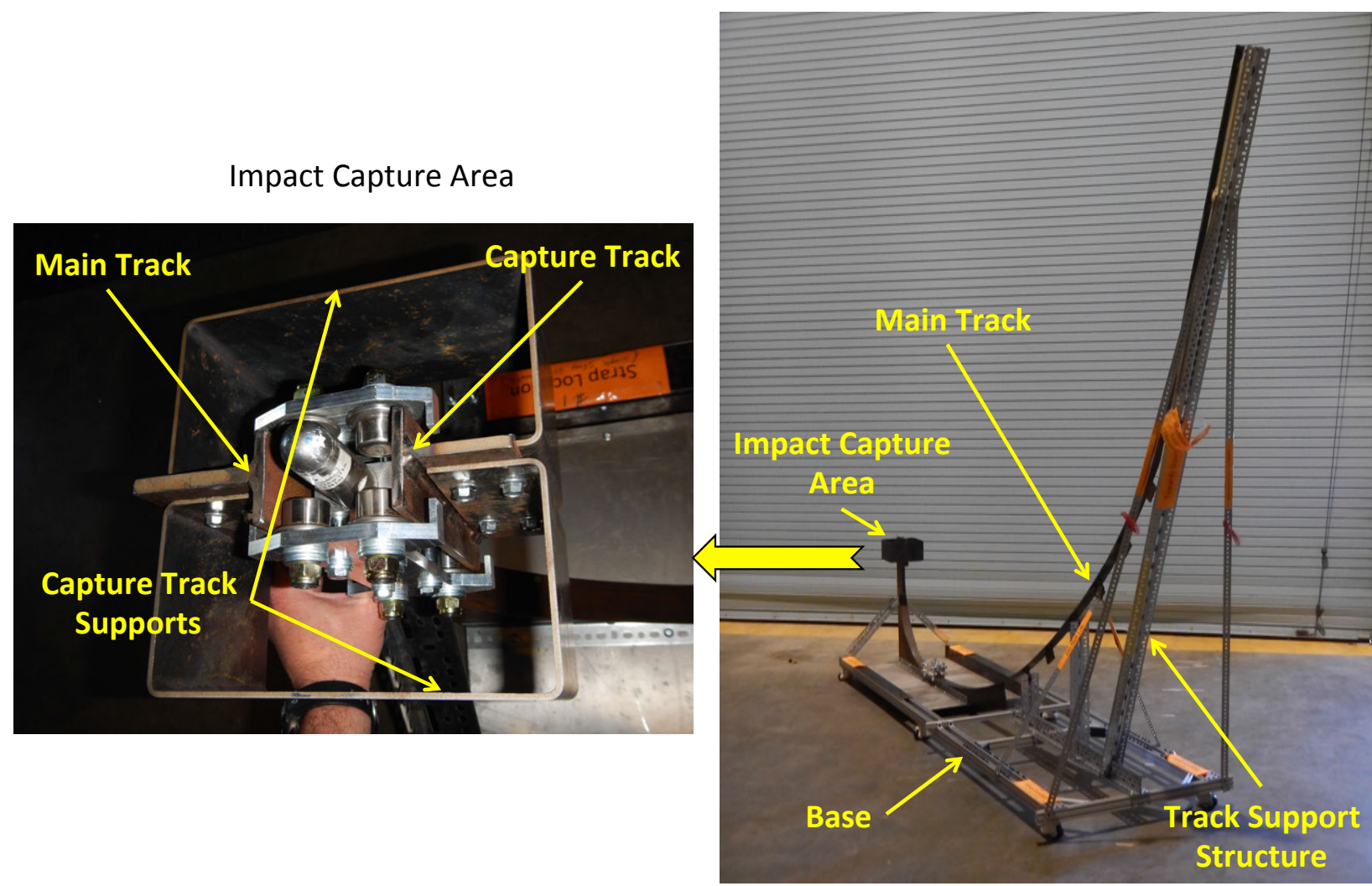

Figure 13. Guided weight impactor track.

making the tight turn prior to impact. The weights were necessary because during the calibration tests, it was found that the friction on the six rubber supports was not sufficient to prevent movement of the track during impacts. The skin impact on the center keel, impact (E3), is shown in Fig. 18, where the dent depth was 0.085-inches deep and approximately 0.79 inches in diameter. The impact was within about a sixteenth of an inch of the desired location, and velocity was $14.17 \mathrm{ft} / \mathrm{s}$ compared to the target of $13.89 \mathrm{ft} / \mathrm{s}$, for error of about $2.02 \%$. At the stringer flange location (E2), the impact velocity was $14.61 \mathrm{ft} / \mathrm{s}$ compared to the target of $14.65 \mathrm{ft} / \mathrm{s}$, for an error of $-0.27 \%$. Lastly, at the frame flange location (E1), the impact velocity was $15.75 \mathrm{ft} / \mathrm{s}$ compared to the target of $16.04 \mathrm{ft} / \mathrm{s}$, for an error of about $-1.81 \%$. Table 3 summarizes the target velocities, actual velocities, and errors for the three interior impacts.

\section{Concluding Remarks}

Impacts to generate BVID on the MBB test article were carried out at the NASA LaRC COLTS Facility. Interior impacts were conducted using an existing spring-loaded device, while the exterior impacts were conducted using a newly developed guided drop weight impactor. The guided drop weight impactor was able to achieve repeatable velocities at impact, within a couple of percent, while at the same time impacting the MBB at the required location within approximately a sixteenth of an inch. The impact velocities (and, therefore, the impact energy) for the three exterior impacts were within $2 \%$ of the desired value. The spring-loaded impactor used to impart the interior BVID had velocity errors up to $8.5 \%$, with the largest error being for the lower velocity. The small error in the gravity-driven impactor emphasizes the accuracy and repeatability of the gravity-driven method. Additionally, the newly developed guided drop weight impactor can be reconfigured in both impact weight and track orientation for use on other large-scale test articles. For impacts to the MBB, only the weight was reconfigured.

\section{Acknowledgements}

The first author thanks Dr. Wade Jackson, also of NASA LaRC, for his assistance in conducting the interior impacts using his spring-loaded impact device. 


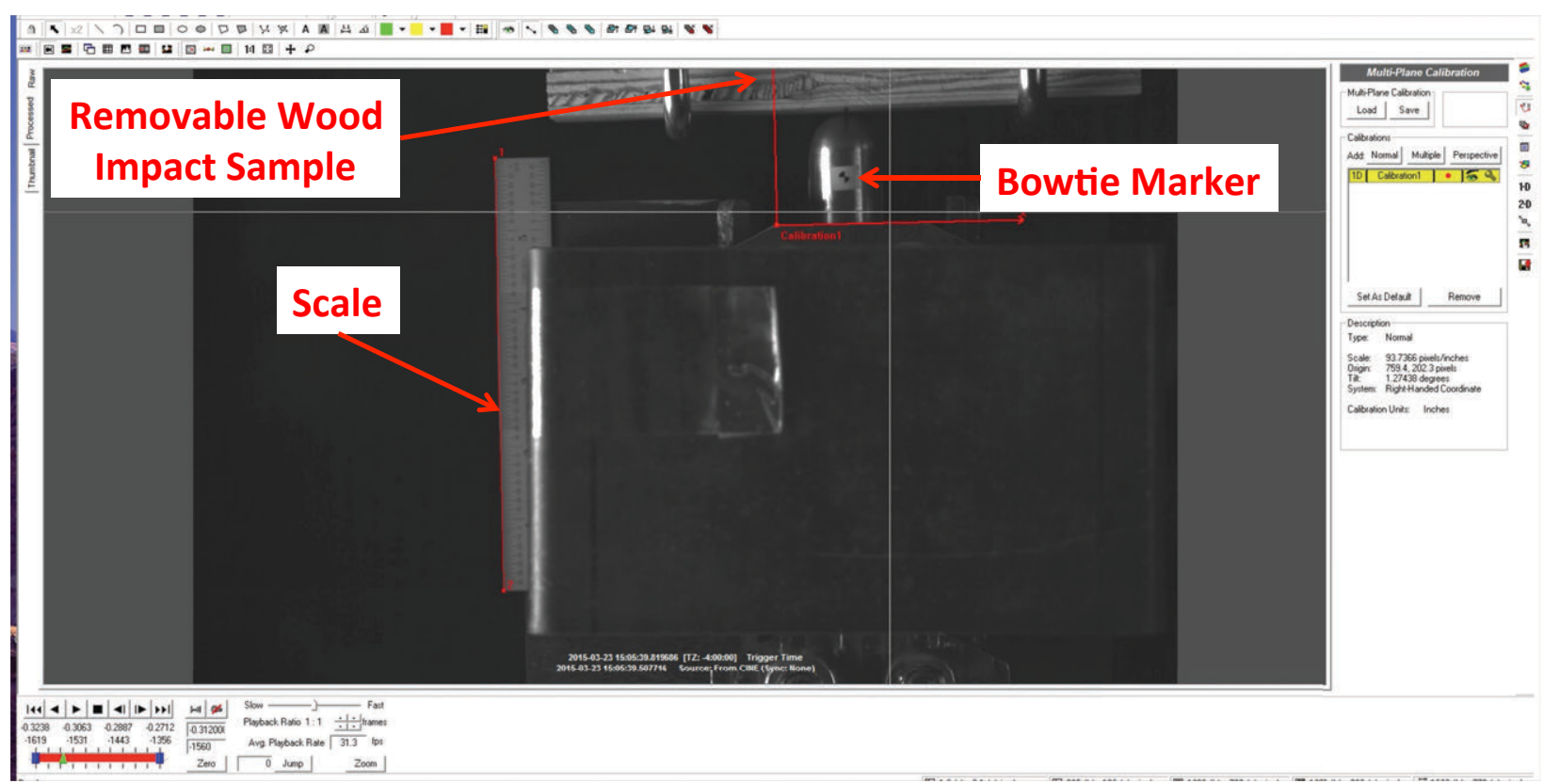

Figure 14. Example velocity measurement screen capture.

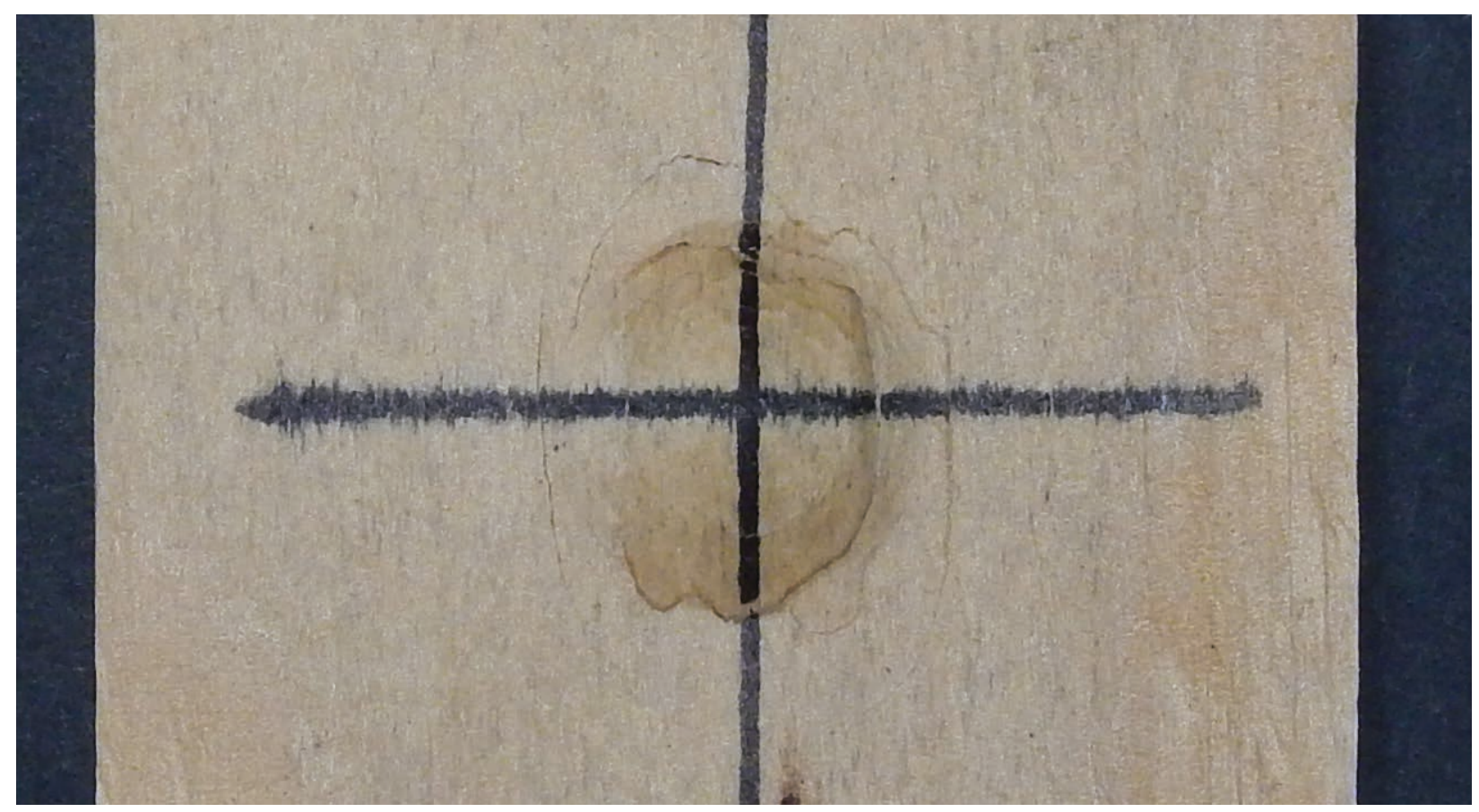

Figure 15. Wood impact sample from 5-lb weight impact test. 


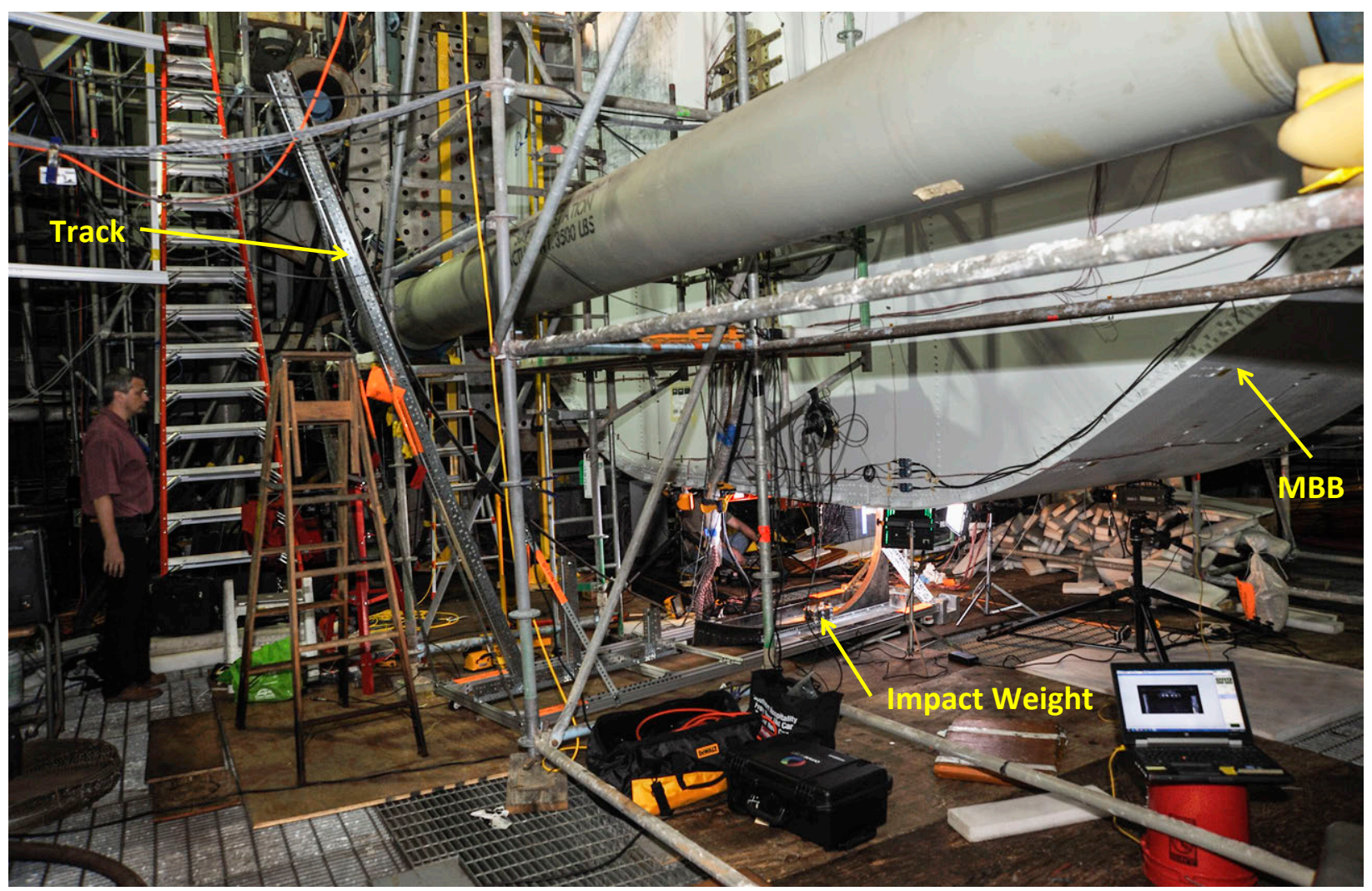

Figure 16. Impactor in COLTS in location to impart exterior skin BVID to MBB keel.

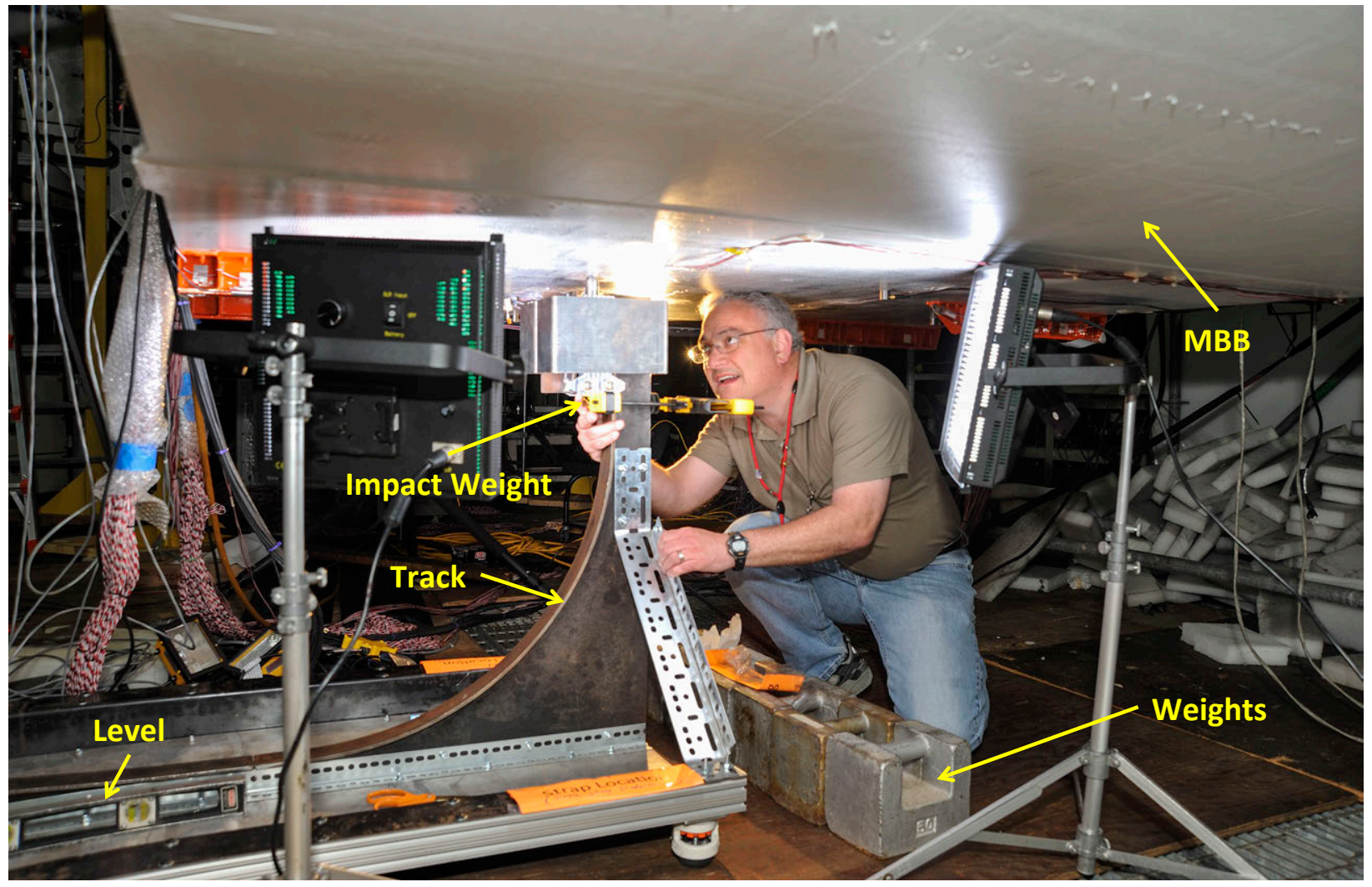

Figure 17. Alignment of impactor for exterior skin impact.

13

American Institute of Aeronautics and Astronautics 


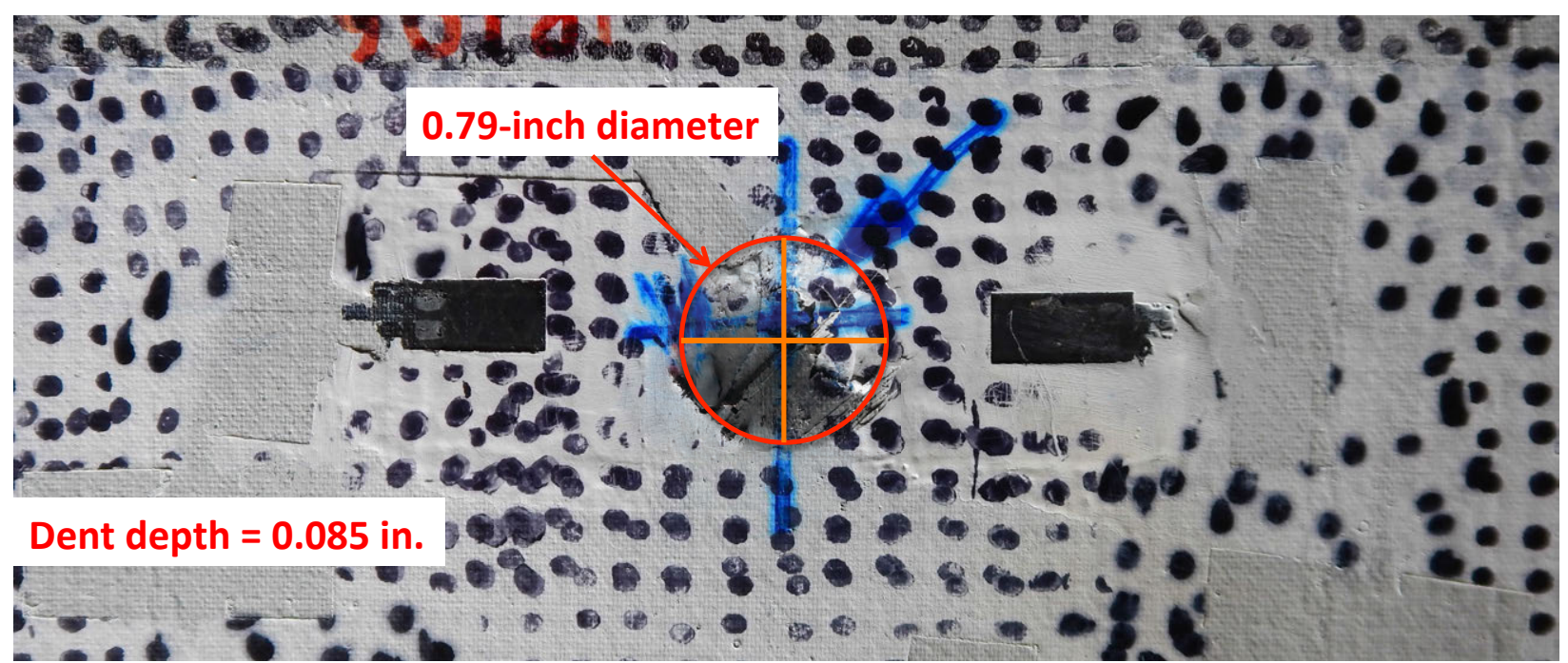

a) Exterior surface, where the blue and orange crosses indicate the target and impact locations, respectively

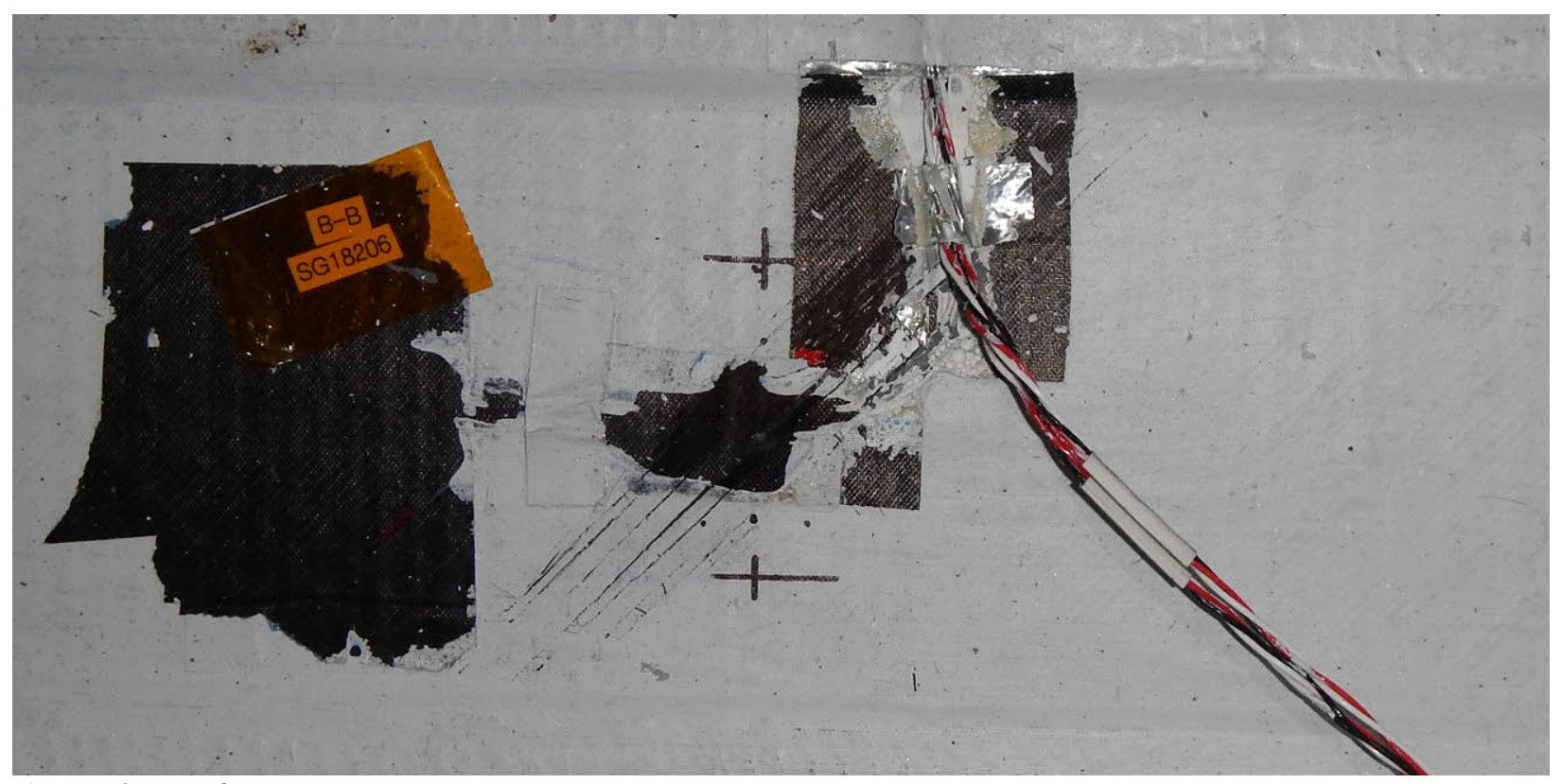

b) Interior surface

Figure 18. Center keel after exterior skin impact.

Table 3. Summary of MBB exterior impact velocities, $\mathrm{ft} / \mathrm{s}$, and percent errors.

\begin{tabular}{|c|c|c|c|c|}
\hline ID & Description & Target Velocity & Actual Velocity & Error (\%) \\
\hline E1 & Keel, Frame Flange & 16.04 & 15.75 & -1.81 \\
\hline E2 & Keel, Stringer Flange & 14.65 & 14.61 & -0.27 \\
\hline E3 & Keel, Center Skin Bay & 13.89 & 14.17 & 2.02 \\
\hline
\end{tabular}




\section{References}

${ }^{1}$ Velicki, A., "Damage Arresting Composites for Shaped Vehicles, Phase I Final Report," NASA CR-2009-215932, 2009.

${ }^{2}$ Velicki, Alex, and Hansen, Dan, "Novel Blended Wing Body Structural Concepts," NRA-03-LaRC-02 Maturation for Advanced Aerodynamic and Structures Technologies for Subsonic Transport Aircraft: Phase I Final Report, 2004.

${ }^{3}$ Hoffman, K., Air Vehicle Technology Integration Program (AVTIP), Delivery Order 0059: "Multi-role Bomber Structural Analysis," AFRL-VA-WP-TR-2006-3067, May 2006, Final Report for December 14, 2004 - May 8, 2006.

${ }^{4}$ Karal, M., "AST Composite Wing Study - Executive Summary," NASA/CR-2001-210650, Prepared for NASA, Langley Research Center under Contract NAS1-20546, 2001.

${ }^{5}$ Velicki, A. and Thrash, P. J., "Advanced Structural Concept Development Using Stitched Composites," AIAA Paper 20082329, 49th AIAA/ASME/ASCE/AHS/ASC Structures, Structural Dynamics, and Materials Conference, Schaumburg, Illinois, April 7-10, 2008.

${ }^{6}$ Lovejoy, A. E., "PRSEUS Pressure Cube Test Data and Response," NASA/TM-2013-217795, 2013.

${ }^{7}$ Yovanov, N., Lovejoy, A. E., Baraja, J., and Gould, K.. "Design, Analysis and Testing of a PRSEUS Pressure Cube to Investigate Assembly Joints," 2012 Airworthiness \& Sustainment Conference, Baltimore, Maryland, April 2-5, 2012.

${ }^{8}$ Rouse, M., "Methodologies for Combined Loads Tests Using a Multi-Actuator Test Machine," presented at the Society for Experimental Mechanics annual meeting, June, 2013.

${ }^{9}$ Rouse, M., and Jegley, D., "Preparation for Testing a Multi-Bay Box Subjected to Combined Loads," presented at the Society for Experimental Mechanics meeting, June, 2015.

${ }^{10}$ Jegley, D. C., Rouse, M., Przekop, A., and Lovejoy, A. E., "Testing of a Stitched Composite Large-Scale Multi-Bay Pressure Box," AIAA Paper 2016-2175, 57th AIAA/ASCE/AHS/ASC Structures, Structural Dynamics, and Materials Conference, San Diego, California, January 3-8, 2016.

${ }^{11}$ Przekop, A., Jegley, D. C., Lovejoy, A. E., Rouse, M., and Wu, T. H., "Testing and Analysis of a Composite NonCylindrical Aircraft Fuselage Structure, Part I: Ultimate Design Loads," AIAA Paper 2016-2176, 57th AIAA/ASCE/AHS/ASC Structures, Structural Dynamics, and Materials Conference, San Diego, California, January 3-8, 2016.

${ }^{12}$ Przekop, A., Jegley, D. C., Lovejoy, A. E., Rouse, M., and Wu, T. H., "Testing and Analysis of a Composite NonCylindrical Aircraft Fuselage Structure, Part II: Severe Damage," AIAA Paper 2016-2177, 57th AIAA/ASCE/AHS/ASC Structures, Structural Dynamics, and Materials Conference, San Diego, California, January 4-8, 2016.

${ }^{13} \mathrm{https}$ ://www.faa.gov/regulations_policies/faa_regulations/, February 18, 2015.

${ }^{14}$ Advisory Circular: Composite Aircraft Structure, AC No. 20-107B, U. S. Department of Transportation, Federal Aviation Administration, September 8, 2009 (Change 1 dated August 24, 2010).

${ }^{15}$ Jackson, W. C., and Polis, D. L., "Use of a New Portable Instrumented Impactor on the NASA Composite Crew Module Damage Tolerance Program," American Society for Composites $29^{\text {th }}$ Conference and $16^{\text {th }}$ US-Japan Conference, La Jolla, CA. September 8-10, 2014.

${ }^{16}$ Lovejoy, A. E., Rouse, M., Linton, K., and Li, V., "Pressure Testing of a Minimum Gauge PRSEUS Panel," AIAA Paper 2011-1813, 52nd AIAA/ASME/ASCE/AHS/ASC Structures, Structural Dynamics and Materials Conference, Denver, Colorado, April 4-7, 2011.

${ }^{17}$ Gould, K., Lovejoy, A. E., Jegley, D., Neal, A. L., Linton, K. A., Bergan, A. C., and Bakuckas, J. G., Jr., "Nonlinear Analysis and Experimental Behavior of a Curved Unitized Stitched Panel," Journal of Aircraft, Vol. 52, No. 2, 2015, pp. 628637.

${ }^{18}$ Lovejoy, A. E., and Przekop, A., "Design and Use of a Guided Weight Impactor to Impart Barely Visible Impact Damage," NASA-TM-2016-218977, 2016.

${ }^{19}$ www.visionresearch.com, March 25, 2015. 